\title{
CORRELATION OF TELOMERE LENGTH SHORTENING WITH SMOKING
}

\author{
María Emilia Vidargas Rubio ${ }^{1}$, Dra. Iliana Herrera ${ }^{1}$, Dra. Abigail Valdes-Bartolo ${ }^{1}$ \\ (iD $₫$, Dra. Ivette Buendia-Roldan *1 (iD $₫$ \\ ${ }^{* 1}$ National Institute of Respiratory Diseases (INER), Mexico
}

DOI: https://doi.org/10.29121/granthaalayah.v9.i1.2021.3113

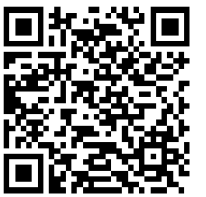

Article Type: Research Article

Article Citation: María Emilia Vidargas Rubio, Dra. Iliana Herrera, Dra. Abigail Valdes -Bartolo, and Dra. Ivette Buendia-Roldan. (2021). CORRELATION OF TELOMERE LENGTH SHORTENING WITH SMOKING. International Journal of Research -GRANTHAALAYAH, 9(1), 211-215. https://doi.org/10.29121/granthaa layah.v9.i1.2021.3113

Received Date: 02 January 2021

Accepted Date: 31 January 2021

Keywords:

Telomeres

Telomere Length

Active Smoking

Passive Smoking

RT-CPR

\section{ABSTRACT}

Background: Telomeres are DNA sequences that can be found at the ends of chromosomes, and prevent them from being damaged, they show shortening every time with the cell division, and when it is below a minimal length, the cells interrupt their cell cycle. Cigarette smoke contains chemical compounds that contribute to the oxidative damage in cells.

Method: subjects over 65 years old belonging to the INER ageing cohort, residents of Mexico City and asymptomatic respiratory patients were studied. A questionary was applied on demographic characteristics, smoking habits (active and passive), and the study groups were identified as active smoking (AS), passive smoking (PS) and non-exposed subjects (NE). Telomere length was measured in a serum sample using the quantitative method based on RT-PCR.

Results: We compared clinical data and telomere length of 333 subjects, showing that non-exposed group are below the 10th percentile, with the smallest telomere size (NE $1.38+0.36$ vs PS $1.50+0.40$ and AS $1.41+0.43$ ).

Conclusion: There is no evidence that telomere shortening have increased as a result of active or passive smoking. It is suggested that smoking is not the only one responsible for the presence of shorter telomeres.

\section{INTRODUCTION}

Telomeres are repeating DNA sequences that can be found at the ends of eukaryotic chromosomes and prevent them from breaking or being damaged. These DNA sequences are highly conserved, with tandem repeats (TTAGGG) and associated proteins, they present a special structure that prevents their binding to the ends of other chromosomes, preventing telomeric fusion[1].

They play an essential role in the preservation of chromosomal integrity, protecting the DNA code from enzymatic action and degradation, contributing to the maintenance of chromosomal stability, and they mediate important interactions between chromosomes and the nuclear matrix, also achieving effects of the transcription of genes located in subtelomeric regions and interact with the regulatory mechanisms of the cell cycle [2],[3].

Currently, it is considered that a minimal of telomere length is required to maintain telomere function, when they reach a critical size, they have difficulty separating during mitosis, generating telomeric associations and chromosomal instability [4],[5].

(C) 2021 The Author(s). This is an open access article distributed under the terms of the Creative Commons Attribution License, which permits unrestricted use, distribution, and reproduction in any medium, provided the original author and source are credited. 
The model proposed about the role of telomeric shortening in ageing and cellular immortality involves several steps. Telomeric DNA protects the ends of chromosomes from recombination events and the length would serve as a "mitotic clock", which allows exit from the cell cycle when the telomeres become short enough. The telomeres length, under physiologically conditions, declines with successive cell divisions, progressively reaching a stage of critical reduction characteristic of the senescence process[6].

Cellular senescence is an irreversible process of decline in proliferation in relation to age. It is an active, genetically programmed process that responds to an induction given by telomeric shortening, generating a similar signal to the produced by DNA damage [7]. That is, telomeres are repeated DNA sequences that are found at the ends of chromosomes and are responsible for preventing the chromosome from degrading or fusing.

In some lung diseases, such as lung cancer, smoking has been reported as an etiological cause, however it has been suggested that there may be other factors that contribute to this causality such as age and genetic susceptibility [8].

Since the cigarette smoke contains a large number of chemical compounds, such as oxidative agents and free radicals, it has been suggested that these agents maximized oxidative damage in the cells, meanwhile the telomere shortening can balance the exposure to these agents and the antioxidant capacity of the body.

Telomere length is also an indicator of the biological age of an individual, therefore, "shorter telomeres associated with increased ageing with all that this involves", such as chronic obstructive pulmonary disease (COPD), cardiovascular diseases and accelerated general deterioration [9].

In this context, we proposed to study the influence of smoking as the only one responsible for a higher shortening in the length of telomeres.

\subsection{MATERIALS AND METHODS}

We studied 333 randomized selected patients over 65 years of age, who participated in the protocol of "Functional and structural lung ageing in adults in Mexico City and early detection of chronic-degenerative respiratory disease" that is carried out in the research unit of the National Institute of Respiratory Diseases (INER).

The screening of the patients for inclusion in the study involves a medical history, a clinical examination, a blood sample and a series of pulmonary function tests, a questionary was also carried out on demographic characteristics, smoking habits, cigarettes per day, the number of years that the person had smoked and the accumulated consumption as a pack-year smoked. We classified the groups as: active smoking (AS), passive smoking (PS) and non-exposed (NE).

Telomere length was measured using a quantitative method based on RT-PCR as described by Cawthon[10]. This technique consists of the polymerase chain reaction in real time (qPCR).

In short, genomic DNA is extracted from peripheral blood samples of 333 individuals, of which 113 with active smoking, 110 passive smoking and 110 without exposure, which served as a control group.

The qPCR was done in triplicate with the genomic DNA extracted from the blood samples and leaving them at a concentration of $1.5 \mathrm{ng} / \mathrm{ml}$, the following reagents were used, power SYBRÒ Green PCR Master Mix (Life Technologies, UK), RNase-free water (SIGMA, UK), a pair of primers targeting the single copy gene (S) (36B4d F300nM), the forward has the sequence CCCATTCTATCATCAACGGGTACAA and the reverse (36B4u R-300nM) CAGCAAGTGGAAGGTGTAATCC and another pair of primers called Tel (T), the forward (900nM) has the sequence CGGTTTGTTTGGGTTTGGGTTTGGGTTTGGGTTTGGGTT and the reverse (900nM) GGCTTGCCTTACCCTTACCCTTACCCTTACCCTTACCCT. The cycling that was used was the following: $95^{\circ} \mathrm{C}$ for $10 \mathrm{~min}$;

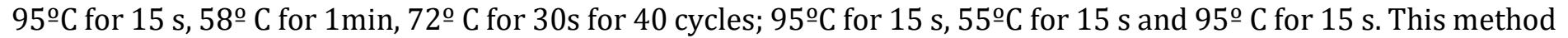
provides a relative value for telomere length (T/S radius) by comparing it with the control curve, which was obtained be extracting DNA from A549 cells obtained from ATCC (Manassas, VA). Outliers were excluded and the average was calculated.

Descriptive statistics were presented as mean and standard deviation (SD). The ANOVA test was used to compared among the three study groups. The correlations between the exposure variables and telomeric length were calculated using the GraphPad Prism V6 program (Graphpad Software Inc, CA, USA), where the logarithmically transformed relative $\mathrm{T} / \mathrm{S}$ ratio was normally distributed. The ANOVA test was also used to compare smoking habits with telomere length groups. 


\section{RESULTS AND DISCUSSIONS}

We analyzed 3 groups: PS ( $n=110)$, AS $(n=113)$ and NE $(n=110)$, the PS group with a mean age of $69 \pm 9$ years old, the AS group with a mean age of $70 \pm 16$ and the NE group with a mean age of $71 \pm 11$. Of the three groups studied, some associated comorbidities were identified such as high blood pressure, diabetes mellitus and gastroesophageal reflux disease (GERD), which although the three comorbidities are not present in all subjects, they do have at least one associated comorbidity. Table 1.

Table 1: General Data in the three groups.

\begin{tabular}{|c|c|c|c|c|}
\hline & $\begin{array}{c}\text { Passive Smoking } \\
\mathrm{n}=110\end{array}$ & $\begin{array}{c}\text { Active Smoking } \\
\mathrm{n}=113\end{array}$ & $\begin{array}{c}\text { Non-Exposed } \\
\mathrm{n}=110\end{array}$ & $\mathrm{P}$ \\
\hline Male Gender (\%) & $8.1(9)$ & $60(68)$ & $22(24)$ & $<0.0001$ \\
\hline Age, years old (SD) & $69(9)$ & $70(16)$ & $71(11)$ & 0.0086 \\
\hline Telomere Size (T/S) (SD) & $1.50(0.40)$ & $1.41(0.43)$ & $1.38(0.36)$ & 0.1929 \\
\hline
\end{tabular}

A higher rate of active smoking was found in male subjects $68 \%$ compared to passive smoking, which were only $9 \%$ of men, subjects in the NE group showed the smallest telomere size (T/S), PS $1.50 \pm 0.40$, AS $1.41 \pm 0.43$ versus $\mathrm{NE} 1.38 \pm 0.36$, there was not statistically significative $(\mathrm{p}=0.2)$ (Fig. 1$)$.

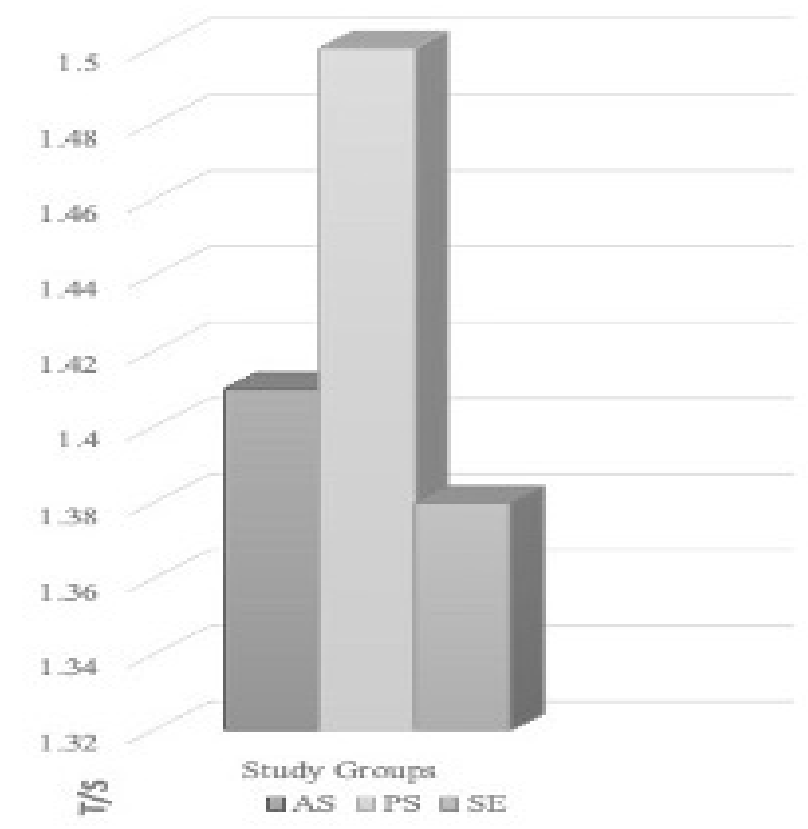

Figure 1. Size of the telomeres graphed in the different study groups AS: 1.41, PS: 1.50 and NE: 1.38 .

Telomere length was determined using the quantitative real-time PCR technique, plotting the T/S value of the three groups AS (black diamonds), PS (blue circles) and NE (red triangles) against this age. The dotted lines represent the $90^{\text {th }}$ and $10^{\text {th }}$ percentiles the $\mathrm{LN}$ (Relative $\mathrm{T} / \mathrm{S}$ radius) is the natural logarithm of the $\mathrm{T} / \mathrm{S}$ radius, where the radius is the number of copies of the telomeric DNA on the single copy gene. Samples that are below the $10^{\text {th }}$ percentile will be those with short telomeres, that belongs to NE group. (Figure 2) 


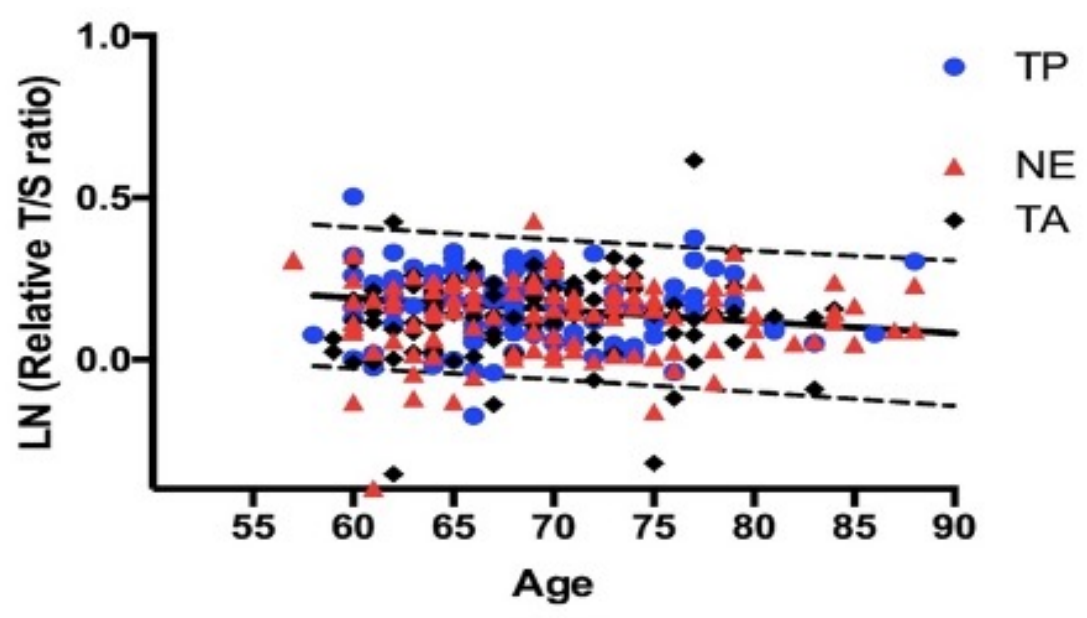

Figure 2. Measurement of telomere length, plotting the T / S value of the three groups: AS (black diamonds), PS (blue circles) and NE (red triangles).

In the present study we have described the telomere length in a population divided according to smoking habit to show its influence, determining that in patients without exposure the shortening was higher compared to patients with both active and passive smoking, confirming the results that was previously described by Zoraida Verde ${ }^{9}$, who showed that a higher shortening of the length of telomeres is related to other exposures suffered by the body and not only with the smoking habit. In this study, we divided the subjects according to active or passive exposure, with the limitation that while for active smoking there is a formula to calculate year packages exposure, to passive smoking is more subjective. In our groups, other associated chronic comorbidities were found that may indirectly influence telomere length.

\section{CONCLUSIONS AND RECOMMENDATIONS}

Based on our results, we consider that lifetime exposure to smoking accumulated, whether active or passive could have a contributing impact on telomere shortening. However, the fact that a person has other exposures may be more related to a higher shortening of telomeres.

We consider that for future studies, the association between exposures and comorbidities could be taken into account as causes of oxidation, they could have a greater relationship with the accelerated shortening of telomeres.

Average telomere lengths were not found to be shortened in subjects exposed to active or passive smoking compared to those not exposed. Therefore, it is suggested that the fact of exposure to cigarette is not the only one responsible for the presence of telomere shortening.

\section{SOURCES OF FUNDING}

This research received no specific grant from any funding agency in the public, commercial, or not-for-profit sectors.

\section{CONFLICT OF INTEREST}

The author have declared that no competing interests exist.

\section{ACKNOWLEDGMENT}

This study was supported by CONACYT Grant \# SECITI/115/2017. 
María Emilia Vidargas Rubio, Dra. Iliana Herrera, Dra. Abigail Valdes -Bartolo, and Dra. Ivette Buendia-Roldan

\section{REFERENCES}

[1] Zakian Va. Telomeres: beginning to understand the end. Science 1995; 270: 1601-7.

[2] Blackburn EH. Structure and function of telomeres. Nature 1991; 350: 569-73.

[3] Holt SE, Wright WE, Shay JW. Regulation of telomerase activity in immortal cells lines. EMBO J 1996; 16: 2932 9.

[4] Counter CM, Avilion AA, Le Feuvre CL, Stewart NG, Greider CW, Harley CB. Telomere shortening associated with chromosome instability is arrested in immortal cells which express telomerase activity. EMBO J. 1992; 11: 1921-9.

[5] Slijepcevic P, Bryant PE. Chromosome healing, telomere capture and mechanisms of radiation-induced chromosome breakage. Int J Radiat Biol 1998; 73: 1-13.

[6] Alejandra S.H. Cottliar, Irma. R. Slavutsky. Telomeros y Actividad de telomerasa: su participacion en el envejecimiento y el desarrollo neoplasico. Buenos Aires Argentina 2000; 60:335-342

[7] Sedivy JM. Can ends justify the means? Telomeres and mechanisms of replicative senescence and immortalization in mammalian cells. Proc Natl Acad Sci USA 1998; 95: 9078-81.

[8] US Department of Health and Human Services (USDHHS). 1981. The health consequences of smoking-the changing cigarette. A report of the Surgeon General, U.S. Government Printing Office, Washington, D.C.

[9] Verde, Z., Reinoso- Barbero, L., Chicharro, L., Garatachea, N., Resano, P., \& Sánchez-Hernandez, I. et al. (2015). Effects of cigarette smoking and nicotine metabolite ratio on leukocyte telomere length. In Elsevier. Madrid España.

[10] Cawthon, R.M. (2002). Telomere measurement by quantitative PCR. Oxford University Press, 30 (10e47). 